\title{
Flufenamic acid promotes angiogenesis through AMPK activation
}

\author{
RUILIANG GE ${ }^{1 *}$, LEI HU $^{1 *}$, YILIN TAI $^{2}$, FENG XUE $^{1}$, LEI YUAN $^{1}$, GONGTIAN WEI $^{1}$ and YI WANG ${ }^{1}$ \\ ${ }^{1}$ Division of Hepatic Surgery II, Eastern Hepatobiliary Hospital, Second Military Medical University, \\ Shanghai 200438; ${ }^{2}$ Laboratory of Neural Signal Transduction, State Key Laboratory of Neuroscience, \\ Institute of Neuroscience, Shanghai Institutes of Biological Sciences, Shanghai 200031, P.R. China
}

Received December 27, 2012; Accepted February 21, 2013

DOI: 10.3892/ijo.2013.1891

\begin{abstract}
Angiogenesis plays critical roles in development, tumor growth and metastasis. Flufenamic acid (FFA) is an anti-inflammatory agent known to alter ion fluxes across the plasma membrane. Its role in angiogenesis has not been fully addressed to date. Here, we report that FFA treatment promotes angiogenesis both in vitro and in vivo. Applying FFA for $12 \mathrm{~h}$ promoted tube formation of human umbilical vein endothelial cells (HUVECs) without affecting cell proliferation. Three angiogenesis-related genes, VEGF, e-NOS and AAMP, were analyzed by RT-PCR. A significant difference was found between the FFA group and the control; the FFA group had significantly higher mRNA accumulation levels of all the three genes $(\mathrm{p}<0.05)$. Moreover, in the chick embryo chorioallantoic membrane (CAM) assay, FFA promoted the formation of macroscopic blood vessels. Finally, western blotting showed that the FFA-treated group had significantly higher phosphorylated AMPK levels, compared with the control $(\mathrm{p}<0.05)$. These results suggest that FFA promotes angiogenesis both in vitro and in vivo likely via promoting tube formation through AMPK activation.
\end{abstract}

\section{Introduction}

Angiogenesis, the formation of new blood vessels, plays important roles in the normal physiological situations, such as embryonic growth and wound healing $(1,2)$. Angiogenesis also has profound impact on pathologic development, particularly on chronic inflammation (3). Evidence has been gathered regarding the association between angiogenesis and inflam-

Correspondence to: Dr Yi Wang or Dr Gongtian Wei, Division of Hepatic Surgery II, Eastern Hepatobiliary Hospital, Second Military Medical University, 225 Chang Hai Road, Shanghai 200438, P.R. China

E-mail: yiwang1265@163.com

E-mail: gongtianwei_pm@163.com

\section{*Contributed equally}

Key words: flufenamic acid, angiogenesis, human umbilical vein endothelial cells, AMPK mation in pathologic conditions. These phenomena have long been coupled together in many chronic inflammation diseases including psoriasis, diabetes, Crohn's disease, rheumatoid arthritis and cancer (4-10). Many of the cells that play a role during inflammation release factors that have profound effects on vascular endothelial cells (11-14). On the other hand, angiogenesis sustains inflammation. Without angiogenesis, cells that present at inflammatory sites will be short of oxygen and nutrients to meet their metabolic needs (15). Thus, these two processes seem to depend on each other. Common molecular mechanisms have also been found to support this idea $(16,17)$. According to this knowledge, direct therapeutic approaches against both chronic inflammation and angiogenesis will become our pursuit. Therefore, to further understand the cross-talk between inflammation and angiogenesis will be an important issue.

Fenamate belongs to a family of non-steroidal anti-inflammatory drugs (NSAIDs). One of the fenamates, flufenamic acid (FFA), is an inhibitor of cyclooxygenase (18) and has been shown to modulate several kinds of ion channels. FFA is commonly used as a blocker of non-selective cation current. It has been shown to inhibit the current of several members of TRP channel superfamily, to potentiate potassium current, to inhibit L-type calcium current, and to inhibit $\mathrm{Ca}^{2+}$-dependent $\mathrm{Cl}$ - current (19-23). The regulation of FFA on C-type TRP channels (TRPC) appears complex since FFA blocks currents of TRPC3 and TRPC7 channels whereas it potentiates the current of TRPC6 channels $(24,25)$. Interestingly, both TRPC3 and TRPC6 have been shown to mediate vascular endothelial growth factor (VEGF)-induced current and TRPC6 also mediates VEGF-induced angiogenesis (26-28). Although FFA affected ion channels have been shown to be involved in angiogenesis, no report is available on the effect of this chemical on angiogenesis.

In the present study, we used HUVECs as a cell model of angiogenesis and the chicken CAM assay as an in vivo angiogenesis model. We investigated the effect of FFA on HUVECs proliferation and tube formation and its role in angiogenesis in chicken CAM.

\section{Materials and methods}

Materials. Flufenamic acid was purchased from SigmaAldrich (USA). BrdU monoclonal antibody was obtained from Neomarkers (USA). Texas-Red-conjugated goat anti-mouse 
secondary antibody was from Molecular Probes. Growth factor-free Matrigel was from BD Biosciences (USA). All cell culture media and reagents were obtained from Invitrogen (Carlsbad, CA, USA).

Cell culture. The HUVECs purchased from Sciencell (USA) were grown in ECM supplemented with 5\% FBS, ECGs and PS in a humidified incubator with $5 \% \mathrm{CO}_{2}$ at $37^{\circ} \mathrm{C}$. The cells were trypsinized with $0.15 \%$ trypsin-EDTA. Passages 3-10 were used for experiments.

Proliferation assay. Cell proliferation was determined by both counting the cell numbers and the BrdU incorporation assay. For counting the cell numbers, HUVECs were seeded at an initial density of $2 \times 10^{5}$ per well in 6-well plates. The FFA was applied at a dose of 20,50 and $100 \mu \mathrm{M}$. Cells were harvested and counted 24, 48 and $72 \mathrm{~h}$ after the treatment. Cell numbers were read in a Beckman Counter. For BrdU incorporation assay, $100 \mu \mathrm{M}$ FFA was applied for $24 \mathrm{~h}$. Then, cells were incubated in the medium with $10 \mu \mathrm{M} \operatorname{BrdU}$ for $3 \mathrm{~h}$ and stained with a monoclonal antibody against $\mathrm{BrdU}$ at $4^{\circ} \mathrm{C}$ for $12 \mathrm{~h}$. A goat anti-mouse IgG labeled with Texas Red was used as secondary antibody. The results were expressed as the percentage of BrdU-positive cells over all the cells.

Tube formation assay. The Matrigel was applied to each well of a 24 -well plate and incubated at $37^{\circ} \mathrm{C}$ for $60 \mathrm{~min}$. The $6 \times 10^{4}$ of endothelial cells was then seeded into each well with the medium containing $0.8 \%$ FCS with or without FFA $(100 \mu \mathrm{M})$. Images of representative 10x fields were taken and endothelial cell tubes were quantified by counting length and branches.

Western blot analysis. The cells were washed twice with PBS and total cellular protein was then extracted in lysis buffer containing $62.5 \mathrm{mM}$ Tris-HCl, 2\% SDS, $10 \%$ glycerol with freshly added proteinase inhibitor cocktail (Sigma, Zwijndrecht, The Netherlands). The protein concentrations were determined by BCA assay (Pierce, Waltham, MA, USA). The protein lysates ( $40 \mu \mathrm{g} / \mathrm{lane})$ were separated by SDS-PAGE and transferred onto nitrocellulose membranes. After blocking with $3 \%$ bovine serum albumin in phosphate-buffered saline, the membranes were incubated with antiphospho-AMPKa and-AMPK $\beta$, or antiphospho-ACC antibody. After washing, the membranes were probed with horseradish peroxidaseconjugated anti-rabbit IgG and the bands were visualized using an ECL-Plus chemiluminescence detection system (GE Healthcare, NJ, USA). To confirm equal loading of proteins, the membranes were probed for $\beta$-actin protein.

Reverse transcription polymerase chain reaction (RT-PCR). HUVECs were lysed with TRIzol Reagent (Invitrogen) and total RNA was extracted according to the manufacturer's instructions. First-strand cDNA was synthesized from $1.5 \mu \mathrm{g}$ of total RNA using Moloney murine leukemia virus reverse transcriptase (M-MLV RT) according to the manufacturer's instructions (Invitrogen). cDNA was amplified by PCR according to the manufacturer's instructions with Taq DNA polymerase (Invitrogen) under the following conditions: $94^{\circ} \mathrm{C}$ for $5 \mathrm{~min}$, followed by 40 cycles of $94^{\circ} \mathrm{C}$ for $30 \mathrm{sec}, 56^{\circ} \mathrm{C}$ for $30 \mathrm{sec}$ and $72^{\circ} \mathrm{C}$ for $90 \mathrm{sec}$, with a final elongation step of
$10 \mathrm{~min}$ at $72^{\circ} \mathrm{C}$. The primer informations are as follows: VEGF: forward, 5'-CTACCTCCACCATGCCAAGT-3'; reverse, 5'-TTT CTTGCGCTTTCGTTTTT-3'; AAMP: forward, 5'-CTTTGC ATTGCACTCAGCAT-3'; reverse, 5'-CAGTCACCATTCGGG ACTTT-3'; e-NOS: forward, 5'-GGCTCCCTCCTTCCGG CTG-3'; reverse, 5'-TAGCCGCACGACGCCCT-3'; GAPDH: forward, 5'-AGCCACTGCTGTGCTTTTAAG-3'; reverse, 5'-CCAAAACCAATGATCTCATCC-3'. The products were electrophoresed in $2 \%$ agarose gel and stained with ethidium bromide.

Angiogenesis in chick embryo CAM. Angiogenesis was assayed using the chick embryo CAM assay according to the method described previously (29). Briefly, fertilized chicken eggs were treated with ethanol $(70 \%)$ and then incubated at $37^{\circ} \mathrm{C}$. On day 3, 2-3-ml albumen was aspirated at the acute pole using a sterile $25-\mathrm{G}$ hypodermic needle in order to allow detachment of the developing CAM from the eggshell. After the removal of albumen, we cut a square window $\sim 10 \times 10 \mathrm{~mm}$ into the shell and sealed the window with transparent tapes. Eggs were then incubated in a horizontal position. Six days later, we opened the window and implanted a $1-\mathrm{mm}^{3}$ sterilized gelatin sponge containing DMSO or FFA onto the CAM. On day 12, the embryos of CAM were fixed by Bouin's fluid and the distribution and density of CAM vessels next to the site of grafting were analyzed.

Statistical analyses. All experiments were repeated three times independently. Data were presented as mean \pm SEM. or as percentage of control. Statistical comparisons between groups were performed using the Student's t-test. $\mathrm{p}<0.05$ was considered statistically significant.

\section{Results}

FFA suppressed HUVEC growth. To test whether FFA plays a role in angiogenesis, we first investigated the effect of FFA on HUVEC growth. The cells were incubated with DMSO, 20, 50 and $100 \mu \mathrm{M}$ FFA for 24, 48 and $72 \mathrm{~h}$ before the cell numbers were determined. As shown in Fig. 1, FFA at the concentration of $20 \mu \mathrm{M}$ had no effect on HUVEC growth at any timepoint. FFA at the concentration of $50 \mu \mathrm{M}$ had weak effect on HUVEC growth. The cell number was slightly reduced at the concentration of $50 \mu \mathrm{M}$ after $72 \mathrm{~h}$, however, there was no significant difference compared with DMSO control. When $100 \mu \mathrm{M}$ FFA was applied to HUVEC, the numbers of the HUVEC started to reduce after $48 \mathrm{~h}$ and was greatly reduced after $72 \mathrm{~h}$. No apoptosis was found at this concentration (data not shown).

FFA reduced HUVEC proliferation. It has been reported that FFA inhibits cell proliferation in other cell types (30-32). We next determined whether the effect of FFA on HUVEC cell number was due to its influence on cell proliferation. To address this question, we applied the BrdU incorporation assay. HUVECs were treated with $100 \mu \mathrm{M}$ FFA for $24 \mathrm{~h}$ before they were incubated with $10 \mu \mathrm{M}$ BrdU for another $3 \mathrm{~h}$. BrdU is an analog of DNA precursor thymidine. When cells are proliferating, BrdU can be incorporated into DNA similarly to thymidine. In this way, the amount of the BrdU in 
A
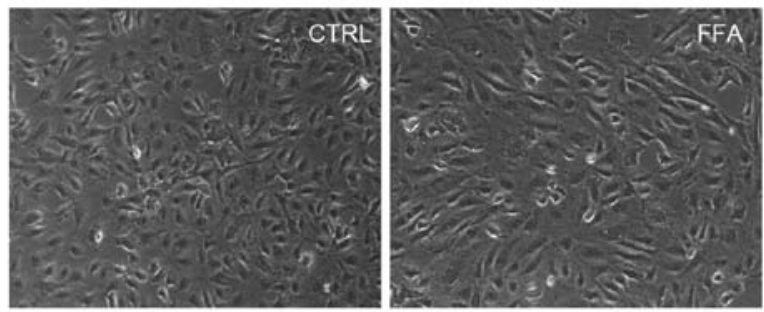

B

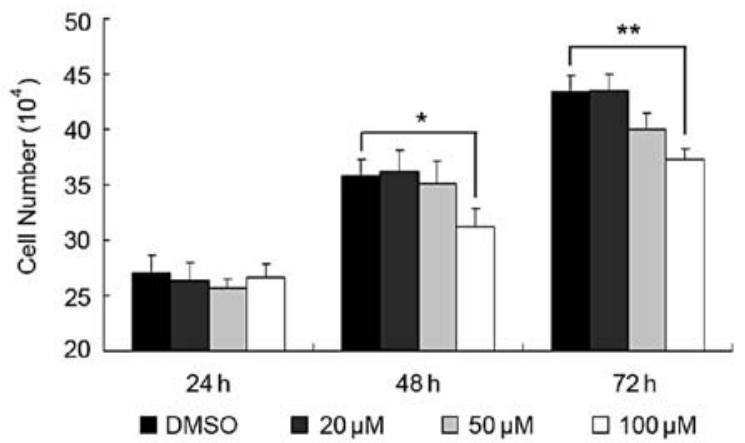

Figure 1.The effect of FFA on HUVEC cell growth. (A) Representative images of HUVECs treated with DMSO or $100 \mu \mathrm{M}$ FFA for $72 \mathrm{~h}$. (B) Statistical analysis of cell numbers of HUVEC treated with DMSO, 20, 50 and $100 \mu \mathrm{M}$ for 24,48 and $72 \mathrm{~h}$. There was a significant reduction in cell numbers in the $100-\mu \mathrm{M}$ group for both 48 and $72 \mathrm{~h}\left({ }^{*} \mathrm{p}<0.05,{ }^{* *} \mathrm{p}<0.01 \mathrm{vs}\right.$. DMSO).

the cells reflects the proliferation rate of the cells. As shown in Fig. 2, the percentage of BrdU-positive cell in DMSO and FFA-treated group was $12 \pm 0.86$ and $8.65 \pm 0.49 \%$, respectively. There was a significant reduction of the percentage of BrdUpositive cells in the FFA treatment group compared with the control group $(\mathrm{p}<0.05)$.

FFA promoted tube formation of HUVECs. In vitro assays of tube formation using endothelial cells are commonly used to study critical steps of angiogenesis (33). We then examine the effect of FFA on tube formation using HUVECs cultured on Matrigel. The tube-like structure appeared $12 \mathrm{~h}$ after the HUVECs were seeded. The total tube length and the number of branching points were analyzed as indexes of angiogenesis.

We applied FFA to HUVECs when they were seeded on Matrigel. As shown in Fig. 3A, after 12 h, FFA greatly increased the formation of tube structure. Both total tube length and branching points were significantly increased in FFA treatment group. The relative total tube length of FFA-treated group increased $50.4 \%$ compared with that of control group (Fig. 3B). The average branching points per field of FFA-treated group increased $135 \%$ compared with that of control group (Fig. 3C). Together, these results suggest that FFA promotes angiogenesis without promoting endothelial cell proliferation.

FFA induced AMPK activation. FFA is one of the Naryanthranilic acid derivatives, belonging to the fenamate group of NSAIDs (34). To examine whether FFA regulates angiogenesis through AMPK activation, phospho-AMPK $\alpha$ and-AMPK $\beta$ and phospho-ACC were measured by western

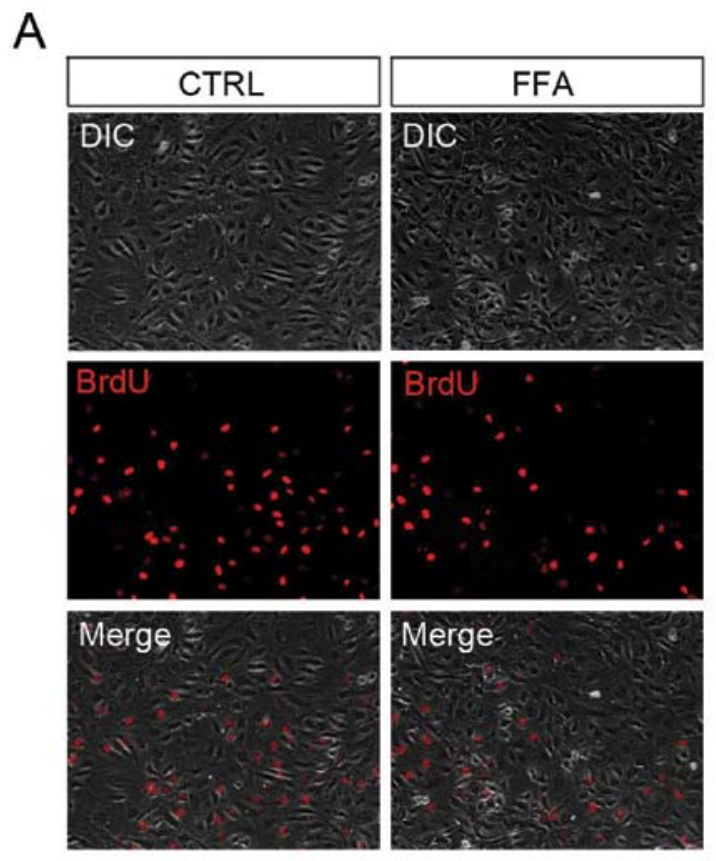

$\mathrm{B}$

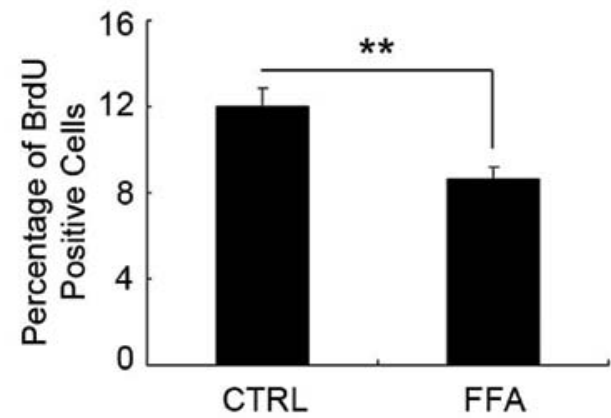

Figure 2. FFA reduced BrdU incorporation in HUVECs. (A) Representative images of BrdU-positive HUVECs treated with DMSO or $100 \mu \mathrm{M}$ FFA for $24 \mathrm{~h}$. (B) Statistical analysis of percentage of BrdU-positive cells in control group and FFA-treated group. The percentage of BrdU-positive cells in FFAtreated group was significantly less than that of the control group $\left({ }^{* *} \mathrm{p}<0.01\right.$ vs. ctrl).
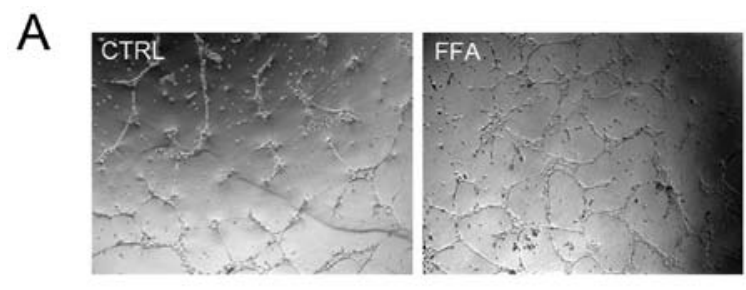

B
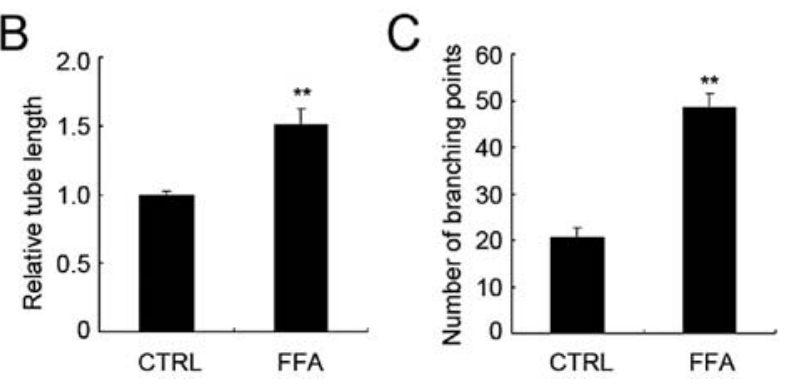

Figure 3.FFA promoted HUVECs capillary tube formation.(A) Representative images of tube formation in HUVECs treated with DMSO and $100 \mu \mathrm{M}$ FFA for $12 \mathrm{~h}$. Quantifications of relative tube length (B) and number of branching points (C) in HUVECs treated with DMSO or FFA ( ${ }^{* *} \mathrm{p}<0.01$ vs. ctrl). 
A

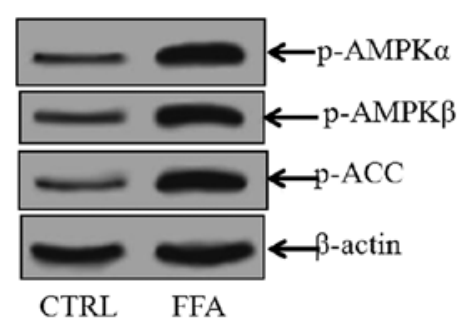

B

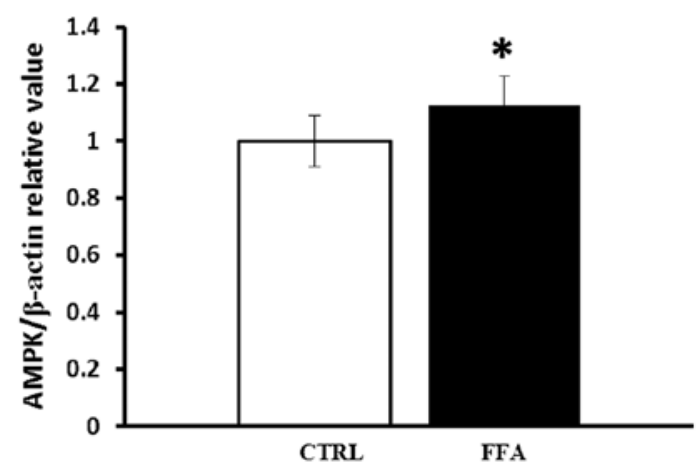

Figure 4. Effects of FFA on AMPK activation. Cellular protein was extracted and subjected to western blot analysis for the phosphorylated levels of AMPK $\alpha$, AMPK $\beta$ and ACC. The equal loading of protein in each lane was verified by probing the blots with an anti- $\beta$-actin antibody. Results are representative of three separate experiments.

blotting. As shown in Fig. 4, incubation of HUVECs with FFA resulted in increased levels of phosphorylated AMPK $\alpha$ and AMPK $\beta$, which was associated with paralleled elevation of phosphorylated ACC, one of the AMPK substrates (35). Compared with control, FFA-treated group had significantly higher phosphorylated AMPK levels $(\mathrm{p}<0.05)$.

Expression of angiogenesis markers. Vascular endothelial growth factor (VEGF), endothelial NO synthase (e-NOS), the angio-associated migratory cell protein (AAMP) are three angiogenesis related genes, which were strongly expressed in endothelial cells (36). The mRNA levels of VEGF, e-NOS and AAMP were measured by RT-PCR. Expression of all three angiogenesis related genes is shown in Fig. 5. There was a significant difference between FFA group and control, FFA group had a significantly higher mRNA accumulation level of all the three angiogenesis related genes $(p<0.05)$.

The effect of FFA on angiogenesis in vivo. We further examined the possible effect of FFA on angiogenesis in vivo. In order to explore the role of FFA in vivo, we applied the chicken chorioallantoic membrane (CAM) assay. We implanted a $1-\mathrm{mm}^{3}$ sterilized gelatin sponge which contained PBS or FFA onto the chorioallantoic membrane for $\sim 72 \mathrm{~h}$ for the blood vessel to grow into the sponge. Then the sponge was fixed and the distribution and density of CAM vessels next to the site of grafting were analyzed.

As shown in Fig. 6, the vessel density in the CAM implanted with the gelatin sponge containing PBS was $15.99 \pm 1.30$. The vessel density in the CAM implanted with the gelatin sponge containing FFA was $23.74 \pm 1.82$, which was a significant increase compared with the control group. These results suggest that FFA promotes angiogenesis in vivo.

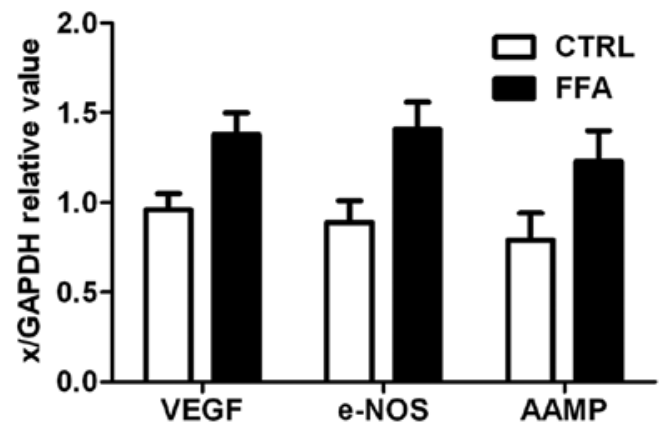

Figure 5. RT-PCR analysis of VEGF, AAMP, e-NOS expression in HUVECs. Control cells and cells treated with $100 \mu \mathrm{M}$ FFA were grown in the same conditions. Data are expressed as the percentage of FFA-stimulated levels of p-AMPK. The constitutively expressed GAPDH was used as an internal control ("p $<0.05$ vs. ctrl).

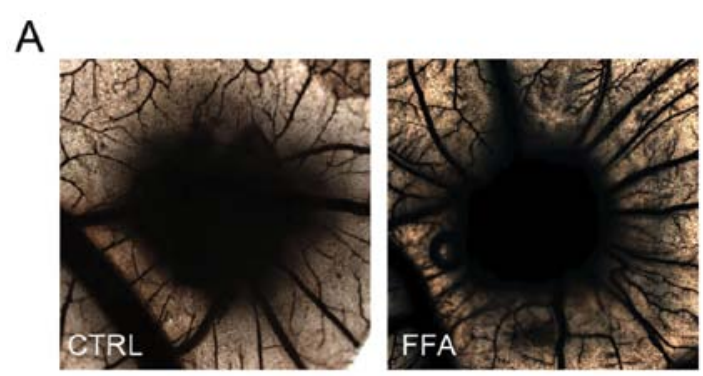

B

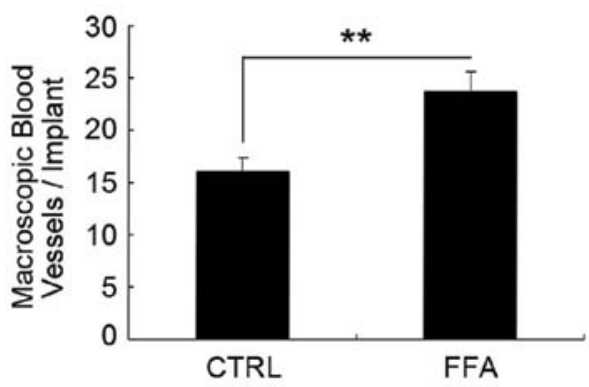

Figure 6. FFA enhanced angiogenesis in vivo. (A) Representative images of the vessel formation in the absent or present of FFA. (B) Quantifications of newly formed blood vessels that grew into the gelatin sponge in the control group and FFA-treated group. There was a significant increase of vessel numbers that grew into the gelatin sponge in the FFA-treated group compared to the control group $(* * * 00.01$ vs. ctrl).

\section{Discussion}

Our results indicate that FFA treatment promotes angiogenesis. In the tube formation assay of HUVEC cells, both total tube length and the number of branching points were increased in the FFA treatment group compared to the control group and cell proliferation was not significantly affected at the time when tube formation assay was performed. AMP-activated protein kinase (AMPK) is a key regulator of metabolic homeostasis (35) and has anti-inflammatory effects $(37,38)$. In addition, it promotes angiogenesis, and protects cells from apoptosis (39-41). RT-PCR was used to analyse the expression of VEGF, AAMP, e-NOS and the results showed significantly increased expression in response to FFA-stimulation. These results indicated that FFA promoted angiogenesis in vitro. 
Moreover, FFA can also promote angiogenesis in vivo. In the chicken CAM assay FFA significantly increased the number of vessels that grow into the gelatin sponge. In addition, we observed that FFA can significantly increase the phosphorylated levels of AMPK. Our results thus support the notion that FFA promotes angiogenesis both in vitro and in vivo through AMPK activation.

The process of angiogenesis includes the proliferation of endothelial cells and migration of these cells to form tube-like structures. At the concentration of $100 \mu \mathrm{M}, 12-\mathrm{h}$ FFA treatment did not affect HUVEC proliferation whereas promoted the formation of tube-like structures and it was not until $24 \mathrm{~h}$ that FFA treatment began to inhibit cell proliferation. The differential effect of FFA on tube formation and cell proliferation is probably due to the multiple targets of FFA. FFA has been reported to inhibit cell proliferation in several cell types $(30,42)$. As a non-selective cation blocker, FFA blocks several channels that have been shown to be involved in the process of cell proliferation. For example, TRPM7 is required for MCF-7 cell proliferation (43). TRPC3 has been shown to be necessary for proliferation of SKOV3 cells (44). Whether the effect of FFA on HUVEC proliferation is the result of its inhibitory effect on these channels remains uncertain. The way FFA promotes HUVEC tube formation is probably through its other targets. For instance, FFA-potentiated non-selective cation channel is required for lysophosphatidylcholine-induced monocyte migration (45). FFA can potentiate the current of TRPC6 and TRPC6 has been shown to promote HUVECs tube formation (28). It is thus possible that TRPC6 participates in FFA-induced tube formation.

Common molecular mechanisms have already been shown to regulate both chronic inflammation and angiogenesis $(46,47)$. These two processes seem to depend on each other based on literature $(3,48)$. However, as an anti-inflammatory agent, FFA promotes angiogenesis in our system. Therefore, a careful understanding of the cross-talk between angiogenesis and chronic inflammation is very important for more effective therapies.

In conclusion, our data show that FFA treatment promotes HUVEC tube formation in vitro. In the in vivo experiment using chick CAM assay, FFA also promotes vessels to grow into the gelatin sponge. Moreover, the phosphorylated AMPK levels were significantly higher in FFA-treated group. These data suggest that FFA promotes angiogenesis both in vitro and in vivo.

\section{References}

1. Tonnesen MG, Feng X and Clark RA: Angiogenesis in wound healing. J Investig Dermatol Symp Proc 5: 40-46, 2000.

2. Breier G: Angiogenesis in embryonic development - a review. Placenta 21 (Suppl A): S11-S15, 2000.

3. Costa C, Incio J and Soares R: Angiogenesis and chronic inflammation: cause or consequence? Angiogenesis 10: 149-166, 2007.

4. Coussens LM and Werb Z: Inflammation and cancer. Nature 420 $860-867,2002$

5. Carmeliet P: Angiogenesis in life, disease and medicine. Nature 438: 932-936, 2005.

6. Lusis AJ: Atherosclerosis. Nature 407: 233-241, 2000

7. Trayhurn P and Wood IS: Adipokines: inflammation and the pleiotropic role of white adipose tissue. Br J Nutr 92: 347-355, 2004.

8. Wubben DP and Adams AK: Metabolic syndrome: what's in a name? WMJ 105: 17-20, 2006.
9. Tan TT and Coussens LM: Humoral immunity, inflammation and cancer. Curr Opin Immunol 19: 209-216, 2007.

10. Otani A, Takagi H, Oh H, Koyama S, Matsumura M and Honda Y: Expressions of angiopoietins and Tie2 in human choroidal neovascular membranes. Invest Ophthalmol Vis Sci 40: 1912-1920, 1999.

11. Benelli R, Lorusso G, Albini A and Noonan DM: Cytokines and chemokines as regulators of angiogenesis in health and disease. Curr Pharm Des 12: 3101-3115, 2006.

12. Nathan C: Points of control in inflammation. Nature 420: 846-852, 2002

13. Folkman J: Angiogenesis in cancer, vascular, rheumatoid and other disease. Nat Med 1: 27-31, 1995.

14. Mrowietz U and Boehncke WH: Leukocyte adhesion: a suitable target for anti-inflammatory drugs. Curr Pharm Des 12: 2825-2831, 2006.

15. Lee FH, Haskell C, Charo IF and Boettiger D: Receptor-ligand binding in the cell-substrate contact zone: a quantitative analysis using CX3CR1 and CXCR1 chemokine receptors. Biochemistry 43: 7179-7186, 2004

16. Pacifico F and Leonardi A: NF-kappaB in solid tumors. Biochem Pharmacol 72: 1142-1152, 2006.

17. Nam NH: Naturally occurring NF-kappaB inhibitors. Mini Rev Med Chem 6: 945-951, 2006.

18. Flower RJ: Drugs which inhibit prostaglandin biosynthesis. Pharmacol Rev 26: 33-67, 1974.

19. Naziroglu M, Luckhoff A and Jungling E: Antagonist effect of flufenamic acid on TRPM2 cation channels activated by hydrogen peroxide. Cell Biochem Funct 25: 383-387, 2007.

20. Peppiatt-Wildman CM, Albert AP, Saleh SN and Large WA: Endothelin-1 activates a $\mathrm{Ca}^{2+}$-permeable cation channel with TRPC3 and TRPC7 properties in rabbit coronary artery myocytes. J Physiol 580: 755-764, 2007.

21. Farrugia G, Rae JL, Sarr MG and Szurszewski JH: Potassium current in circular smooth muscle of human jejunum activated by fenamates. Am J Physiol 265: G873-G879, 1993.

22. Doughty JM, Miller AL and Langton PD: Non-specificity of chloride channel blockers in rat cerebral arteries: block of the L-type calcium channel. J Physiol 507: 433-439, 1998.

23. Greenwood IA and Large WA: Comparison of the effects of fenamates on Ca-activated chloride and potassium currents in rabbit portal vein smooth muscle cells. Br J Pharmacol 116: 2939-2948, 1995.

24. Inoue $\mathrm{R}$, Okada $\mathrm{T}$, Onoue $\mathrm{H}$, et al: The transient receptor potential protein homologue TRP6 is the essential component of vascular alpha(1)-adrenoceptor-activated $\mathrm{Ca}(2+)$-permeable cation channel. Circ Res 88: 325-332, 2001.

25. Jung S, Strotmann R, Schultz G and Plant TD: TRPC6 is a candidate channel involved in receptor-stimulated cation currents in A7r5 smooth muscle cells. Am J Physiol Cell Physiol 282: C347-C359, 2002.

26. Poteser M, Graziani A, Eder P, et al: Identification of a rare subset of adipose tissue-resident progenitor cells, which express CD133 and TRPC3 as a VEGF-regulated $\mathrm{Ca}^{2+}$ entry channel. FEBS Lett 582: 2696-2702, 2008.

27. Hamdollah Zadeh MA, Glass CA, Magnussen A, Hancox JC and Bates DO: VEGF-mediated elevated intracellular calcium and angiogenesis in human microvascular endothelial cells in vitro are inhibited by dominant negative TRPC6. Microcirculation 15: 605-614, 2008 .

28. Ge R, Tai Y, Sun Y, et al: Critical role of TRPC6 channels in VEGF-mediated angiogenesis. Cancer Lett 283: 43-51, 2009.

29. Ribatti D, Nico B, Vacca A and Presta M: The gelatin spongechorioallantoic membrane assay. Nat Protoc 1: 85-91, 2006.

30. Schober W, Wiskirchen J, Kehlbach R, et al: Flufenamic acid: growth modulating effects on human aortic smooth muscle cells in vitro. J Vasc Interv Radiol 13: 89-96, 2002.

31. Tiemann U, Neels P, Pohland R, Walzel $H$ and Lohrke B Influence of inhibitors on increase in intracellular free calcium and proliferation induced by platelet-activating factor in bovine oviductal cells. J Reprod Fertil 116: 63-72, 1999.

32. Weiser $T$ and Wienrich M: Investigations on the mechanism of action of the antiproliferant and ion channel antagonist flufenamic acid. Naunyn Schmiedebergs Arch Pharmacol 353: 452-460, 1996.

33. Wilson BD, Ii M, Park KW, et al: Netrins promote developmental and therapeutic angiogenesis. Science 313: 640-644, 2006.

34. Chi Y, Li K, Yan Q, et al: Nonsteroidal anti-inflammatory drug flufenamic acid is a potent activator of AMP-activated protein kinase. J Pharmacol Exp Ther 339: 257-266, 2011. 
35. Towler MC and Hardie DG: AMP-activated protein kinase in metabolic control and insulin signaling. Circ Res 100: 328-341, 2007.

36. Del Carratore R, Carpi A, Beffy P, et al: Itraconazole inhibits HMEC-1 angiogenesis. Biomed Pharmacother 66: 312-317, 2012.

37. Aoki C, Hattori Y, Tomizawa A, Jojima T and Kasai K: Antiinflammatory role of cilostazol in vascular smooth muscle cells in vitro and in vivo. J Atheroscler Thromb 7: 503-509, 2010.

38. Shin MJ, Lee YP, Kim DW, et al: Transduced PEP-1-AMPK inhibits the LPS-induced expression of COX-2 and iNOS in Raw264. 7 cells. BMB Rep 43: 40-45, 2010.

39. Kongsuphol P, Cassidy D, Hieke B, et al: Mechanistic insight into control of CFTR by AMPK. J Biol Chem 284: 5645-5653, 2009.

40. Kréneisz O, Benoit JP, Bayliss DA and Mulkey DK: AMP-activated protein kinase inhibits TREK channels. J Physiol 587: 5819-5830, 2009.

41. Klein H, Garneau L, Trinh NTN, et al: Inhibition of the KCa3. 1 channels by AMP-activated protein kinase in human airway epithelial cells. Am J Physiol Cell Physiol 296: C285-C295, 2009.

42. Schlichter LC, Sakellaropoulos G, Ballyk B, Pennefather PS and Phipps DJ: Properties of $\mathrm{K}^{+}$and $\mathrm{Cl}^{-}$channels and their involvement in proliferation of rat microglial cells. Glia 17: 225-236, 1996.
43. Guilbert A, Gautier M, Dhennin-Duthille I, Haren N, Sevestre H and Ouadid-Ahidouch H: Evidence that TRPM7 is required for breast cancer cell proliferation. Am J Physiol Cell Physiol 297: C493-C502, 2009.

44. Yang SL, Cao Q, Zhou KC, Feng YJ and Wang YZ: Transient receptor potential channel $\mathrm{C} 3$ contributes to the progression of human ovarian cancer. Oncogene 28: 1320-1328, 2009.

45. Schilling T and Eder C: Non-selective cation channel activity is required for lysophosphatidylcholine-induced monocyte migration. J Cell Physiol 221: 325-334, 2009.

46. Fiedler U, Reiss Y, Scharpfenecker M, et al: Angiopoietin-2 sensitizes endothelial cells to TNF-alpha and has a crucial role in the induction of inflammation. Nat Med 12: 235-239, 2006.

47. Fiedler U and Augustin HG: Angiopoietins: a link between angiogenesis and inflammation. Trends Immunol 27: 552-558, 2006.

48. Noonan DM, De Lerma Barbaro A, Vannini N, Mortara L and Albini A: Inflammation, inflammatory cells and angiogenesis: decisions and indecisions. Cancer Metastasis Rev 27: 31-40, 2008. 